\title{
REINFORCING EFFECTS AND MECHANICAL PROPERTIES OF RC BEAM WITH CFS UNDER STATIC AND RUNNING LOADS
}

Ming-Chien Hsu

Doctor Course of Graduate school of Industrial Technology, Nihon University, Narashino-shi, Chiba 275-8575., c33830@cit.nihon-u.ac.jp

Tadashi Abe

Professor, Department of Industrial Technology, Nihon University, Narashino-shi, Chiba 275-8575.

Tetsukazu Kida

Professor, Department of Industrial Technology, Nihon University, Narashino-shi, Chiba 275-8575.

Toshiaki Sawano

Associate Professor, Department of Industrial Technology, Nihon University, Narashino-shi, Chiba 275-8575.

Kazuhiko Minakuchi

Research Fellow, Department of Industrial Technology, Nihon University, Narashino-shi, Chiba 275-8575.

Follow this and additional works at: https://jmstt.ntou.edu.tw/journal

Part of the Mechanical Engineering Commons

\section{Recommended Citation}

Hsu, Ming-Chien; Abe, Tadashi; Kida, Tetsukazu; Sawano, Toshiaki; and Minakuchi, Kazuhiko (2006) "REINFORCING EFFECTS AND MECHANICAL PROPERTIES OF RC BEAM WITH CFS UNDER STATIC AND RUNNING LOADS," Journal of Marine Science and Technology. Vol. 14: Iss. 2, Article 2.

DOI: $10.51400 / 2709-6998.2060$

Available at: https://jmstt.ntou.edu.tw/journal/vol14/iss2/2

This Research Article is brought to you for free and open access by Journal of Marine Science and Technology. It has been accepted for inclusion in Journal of Marine Science and Technology by an authorized editor of Journal of Marine Science and Technology. 


\title{
REINFORCING EFFECTS AND MECHANICAL PROPERTIES OF RC BEAM WITH CFS UNDER STATIC AND RUNNING LOADS
}

\author{
Ming-Chien Hsu*, Tadashi Abe**, Tetsukazu Kida**, Toshiaki Sawano***, \\ and Kazuhiko Minakuchi****
}

Key words: RC beam, static load, running load, reinforcing effects.

\section{ABSTRACT}

Through a series of experiments on RC beams reinforced with the carbon fiber sheet (CFS) under the static and running loads, the authors verified the effects of the aspect ratio (ratio of beam width to depth) and CFS reinforcement on the failure mechanism. The experiments revealed that: (1) CFS can effectively reinforce beams subjected to static loads in the flexural region, and increase the strength of beams subjected to running loads but such beams failed in shear, and (2) the tensile strength of CFS is greatly influenced by the aspect ratio. The authors evaluated how the aspect ratio influences the strength increasing effect of CFS; in addition, developed a theoretical equation for calculating the ultimate bending strength of RC beams reinforced with CFS, and approximated the experimental results by the theoretical results derived from the equation.

\section{INTRODUCTION}

The adhesion of carbon fiber sheet (CFS) offers various advantages such as the construction ability and the reduction of construction time. Therefore, it has been recently found in the increasing applications to the strengthening of $\mathrm{RC}$ beam and the repair of cracked structural member. This strengthening method has been the subject of a number of studies leading to reports on suitable design methods, mechanisms and its reinforcing effects [3, 8-10, 12, 14, 15].

As for the flexural and shear load-carrying capacities of RC beam under running loads, it is well known to be considerably lower than under static load $[1,7,11]$.

Paper Submitted 04/12/05, Accepted 07/05/05. Author for Correspondence: Ming-Chien Hsu. E-mail: c33830@cit.nihon-u.ac.jp.

*Doctor Course of Graduate school of Industrial Technology, Nihon University, Narashino-shi, Chiba 275-8575.

**Professor, Department of Industrial Technology, Nihon University, Narashino-shi, Chiba 275-8575.

***Associate Professor, Department of Industrial Technology, Nihon University, Narashino-shi, Chiba 275-8575.

****Research Fellow, Department of Industrial Technology, Nihon University, Narashino-shi, Chiba 275-8575.
Particularly, the RC beam under the running loads results in shear failure rather than flexural failure $[1,2,6$, 7]. Accordingly, it is very important to clarify the reinforcing effect of CFS in the shear span of RC beam.

The present paper deals with the effects of the aspect ratio of $\mathrm{RC}$ beam reinforced with $\mathrm{CFS}$ on the beam failure mechanism. Three types of experimental specimens with different cross-sections were used. In the event of evaluating the flexural load-carrying capacity of RC beams reinforced with the CFS, the strength increasing effect of CFS is influenced greatly by the aspect ratio (that is the ratio of width $\left(b_{w}\right)$ to height $(h)$ ) of RC the beams. Therefore, the authors have tried to introduce a correction factor of reinforcing effect to evaluate the effects of the aspect ratio on the strengthening effect of CFS and have proposed theoretical loadcarrying capacity equations.

\section{PREPARATION OF EXPERIMENTAL SPECIMENS}

\section{Materials used for experimental specimens}

Ordinary Portland cement and coarse aggregate with a maximum size of $20 \mathrm{~mm}$ were used for the experimental specimens. The D16 reinforcements of SD 295A type were used. The physical properties of concrete and reinforcements are listed in Table 1. The high-strength continuous carbon fiber sheet with a unit weight of $202 \mathrm{~g} / \mathrm{m}^{2}$, a thickness of $0.111 \mathrm{~mm}$, and a width of $30 \mathrm{~cm}$ was used. The physical properties of CFS are listed in Table 2. The epoxy resin was used as an adhesive agent (The adhesive strength to concrete: $2.6 \mathrm{~N} / \mathrm{mm}^{2}$ ).

\section{Specimen size and reinforcement arrangement}

The aspect ratios at which shear failures occur under the running loads were previously investigated [7]. According to the experimental results, the shear failure became dominant when the width $\left(b_{w}\right)$ was less 
Table 1. Physical properties of concrete and reinforcements

\begin{tabular}{ccccc}
\hline \multirow{2}{*}{$\begin{array}{c}\text { Test } \\
\text { specimen }\end{array}$} & $\begin{array}{c}\text { Compressive } \\
\text { strength of } \\
\text { concrete } \\
\left(\mathrm{N} / \mathrm{mm}^{2}\right)\end{array}$ & $\begin{array}{c}\text { Yield strength } \\
\left(\mathrm{N} / \mathrm{mm}^{2}\right)\end{array}$ & $\begin{array}{c}\text { Tensile } \\
\text { strength } \\
\left(\mathrm{N} / \mathrm{mm}^{2}\right)\end{array}$ & $\begin{array}{c}\text { Young's } \\
\text { modulus } \\
\left(\mathrm{N} / \mathrm{mm}^{2}\right)\end{array}$ \\
\cline { 5 - 5 } & 38.5 & & & \\
Type I & 41.5 & 368 & 568 & 196 \\
Type II & 30.0 & 373 & 544 & 200 \\
Type III & & & & \\
\hline
\end{tabular}

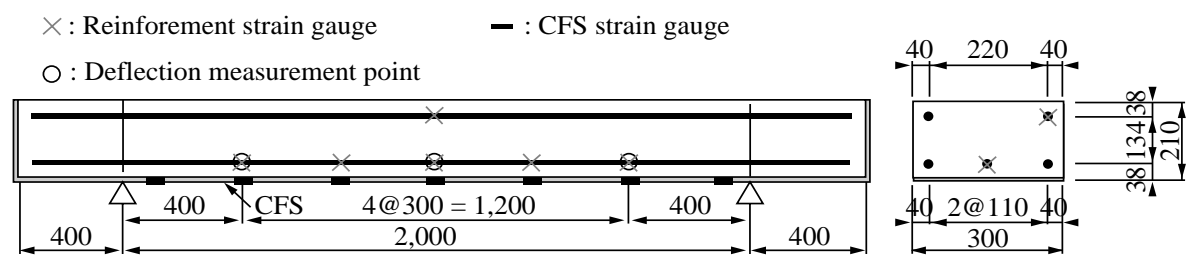

(1) Type I

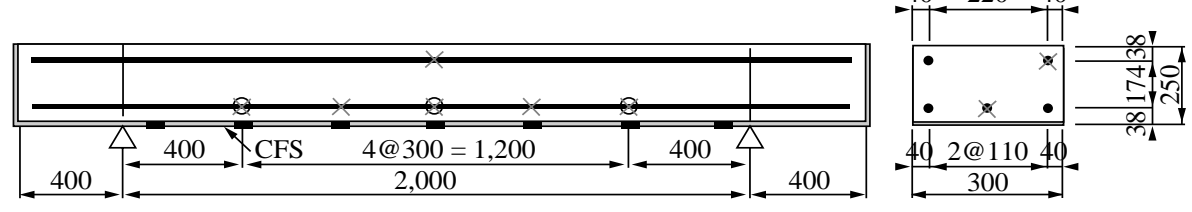

(2) Type II

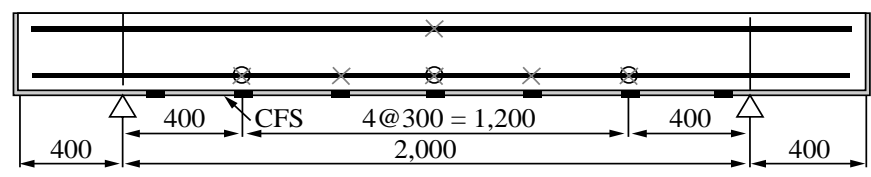

(3) Type III

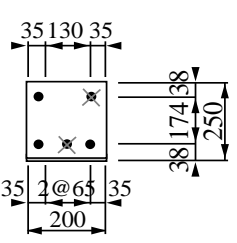

(Unit: $\mathrm{mm}$ )

Fig. 1. Specimen size and reinforcements arrangement.

Table 2. Physical properties of CFS

\begin{tabular}{cccc}
\hline $\begin{array}{c}\text { Reinforcing } \\
\text { material }\end{array}$ & $\begin{array}{c}\text { Unit weight } \\
\left(\mathrm{g} / \mathrm{m}^{2}\right)\end{array}$ & $\begin{array}{c}\text { Tensile strength } \\
\left(\mathrm{N} / \mathrm{mm}^{2}\right)\end{array}$ & $\begin{array}{c}\text { Young's modulus } \\
\left(\mathrm{kN} / \mathrm{mm}^{2}\right)\end{array}$ \\
\hline Carbon fiber & 202 & 4,420 & 243 \\
\hline
\end{tabular}

than the effective depth (d) of the RC beam. Therefore, the three types of RC beam specimens with different widths and depths were prepared. The specimen sizes and the selected measuring points are shown in Figure 1. The RC beam specimens not reinforced with CFS and those reinforced with CFS are referred to as "nonreinforced RC beams" and "CFS-reinforced RC beams, " hereafter.

(1) Type I: It had the span of $200 \mathrm{~cm}$, the width of $30 \mathrm{~cm}$ and the height of $21 \mathrm{~cm}$ as to the cross-section. There were three reinforcements on the tension sides with the effective depth of $17.2 \mathrm{~cm}$ and two reinforcements on compression sides.

(2) Type II: It had the span and the width same as Type I, but the height was $25 \mathrm{~cm}$. The arrangement of the reinforcements were same as Type I, but the effective depth was $21.2 \mathrm{~cm}$.

(3) Type III: It had the span same as Type I, the height same as Type II, but the width is $20 \mathrm{~cm}$. The arrangement of the reinforcements were same as Type I, but the effective depth was same as Type II.

\section{CFS Bonding procedure}

A single layer of CFS was bonded to the bottom of 
beam specimen in the direction of the primary reinforcement. The CFS was bonded over the whole bottom surface over the supports for Types I and II. For Type III, CFS was applied between both supports only.

\section{OUTLINE OF EXPERIMENTS}

\section{Flexural experiment under static load}

This was a flexural experiment in which a wheel was rest at the center of the span (that was at the point of maximum flexural stress) as illustrated in Figure 2 (1). The load was increased in increments of $5.0 \mathrm{kN}$ by the loading controller.

\section{Experiment under running load}

The running load was placed at the center of the beam and moved between Supports A and B until finally coming to a stop at the center. This step is illustrated in Figure 2 (2). The load was increased in increments of $5.0 \mathrm{kN}$ at each cycle until the experimental specimen fails.

\section{FAILURE MODES AND MAXIMUM LOAD-CARRYING CAPACITY}

\section{Failure modes}

Figure 3 denotes the cracking patterns occurred during the experiments, and Table 3 also indicates the failure modes inclusively.

\section{(1) Non-reinforced RC Beams}

In the flexural experiments under the static load, all types of RC beam suffered the flexural failure as the

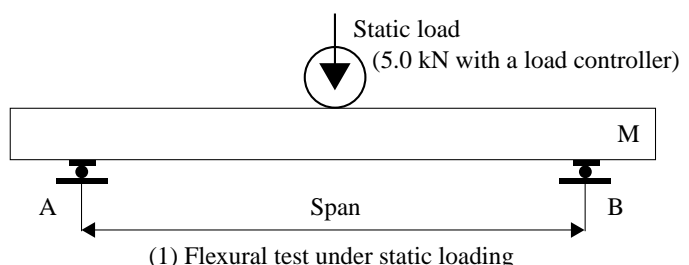

(1) Flexural test under static loading

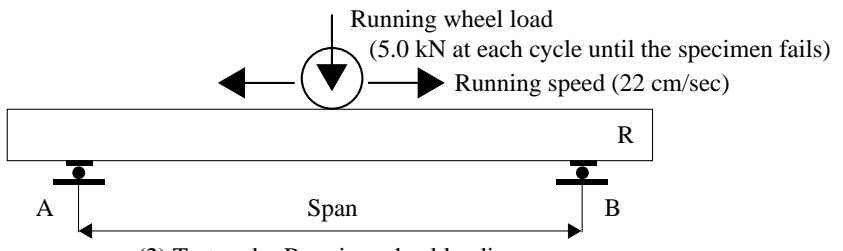

(2) Test under Running wheel loading load was being increased with cracks developing at an angle of 55-60 degrees from a point directly below the wheel (Figures 3 (1a), (2a), and (3a)). In the experiments under the running load, Types I and II suffered the flexural failure as the load was being increased, and Type III suffered the shear failure at a location of $55 \mathrm{~cm}$ away from the Support A disruptively (Figures 3 (1b), (2b), and (3b)).

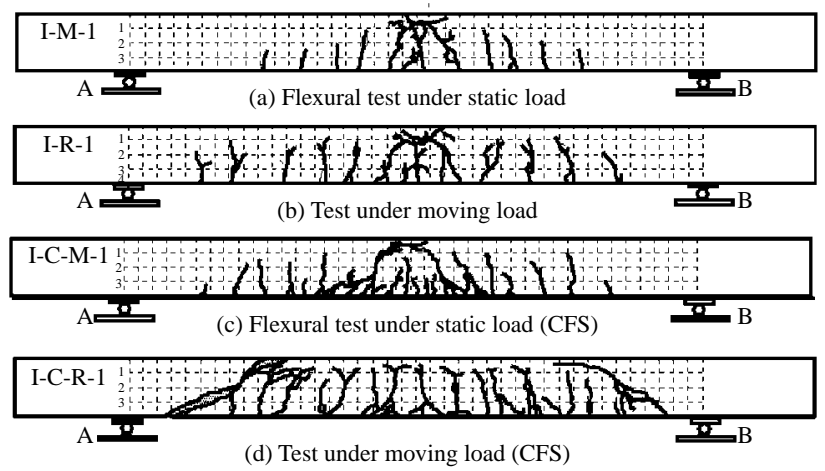

(1) Type I
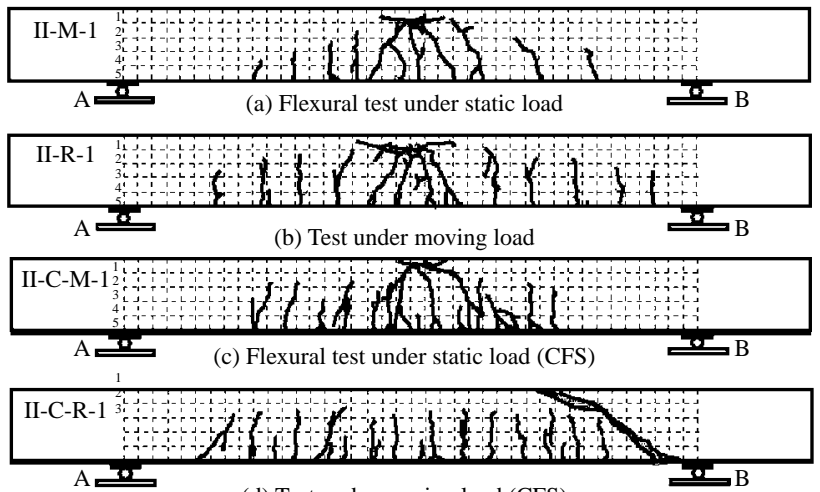

(d) Test under moving load (CFS)

(2) Type II
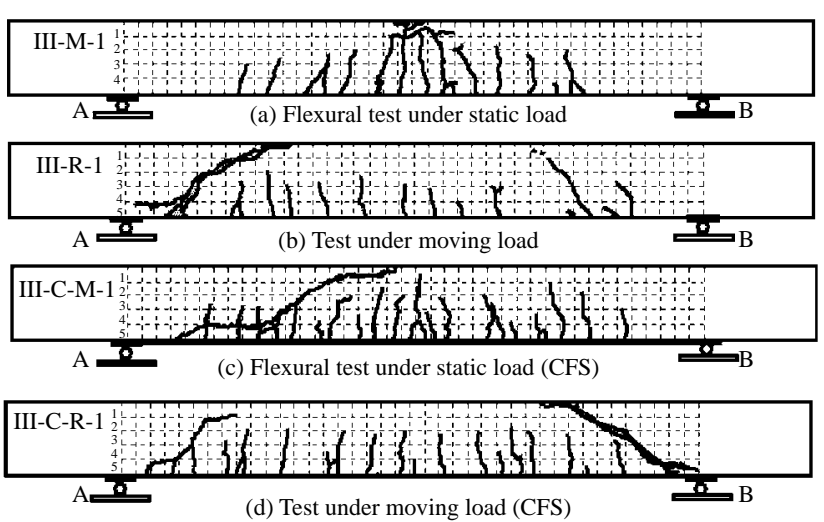

(3) Type III

Fig. 3. Characteristic cracking patterns.

Fig. 2. Loading procedures. 


\section{(2) CFS-reinforced RC beams}

In the flexural experiments under the static load, Types I and II suffered the flexural failure as the load was being increased with cracks developing at an angle of approximately 60 degrees (Figures $3(1 \mathrm{c}),(2 \mathrm{c})$, and (3c)). The cracks occurred at intervals of 5 to $7 \mathrm{~cm}$ apart, and the flexural load-carrying capacity increased as resulting from the crack dispersion effect. Type III suffered the shear failure with many cracks developed and grew away from the CFS as the load was being increased, and another macroscopic cracks developed from the loading point at an angle of 45 degrees. For the CFS, it peeled away from the concrete surface due to the tension at the center of the RC beam, with the peeling progressing toward the supports. The CFS was not torn on any of the specimens.

In the case of Type III, the shear load-carrying capacity was lower than the flexural load-carrying capacity, as shown in Table 3; so, the specimen, III-R1 , without the CFS reinforcement suffered the shear failure. The specimens reinforced with the CFS, which suffered the shear failure, had even greater flexural load-carrying capacity. That means Type III underwent the shear failure.
In the experiments under the running load, the diagonal cracks developed in the shear span from both supports (Figures 3 (1d), (2d), and (3d)). Type I suffered the brittle shear failure at a location of $45 \mathrm{~cm}$ away from Support A $(a / d=2.62 ; a=45 \mathrm{~cm}$, the distance between the failure point and the support; $d=17.2 \mathrm{~cm}$, effective depth). For Type II and III, the corresponding position was $55 \mathrm{~cm}$ away from Support B $(a / d=2.59$; $a=55 \mathrm{~cm}$, the distance between the failure point and the support; $d=21.2 \mathrm{~cm}$, effective depth). These results indicated that the $\mathrm{RC}$ beams reinforced with the CFS had the higher flexural load-carrying capacity, but there was no significant increase in the load-carrying capacity within the shear span that could be expected. Therefore, for all specimen types under the running load, the specimens suffered the shear failure, and the CFS was peeled off simultaneously with the occurrence of failure. In any case, the CFS fracture never occurred.

\section{Maximum load-carrying capacity of RC beams}

The maximum load-carrying capacities of nonreinforced RC beams and CFS-reinforced RC beams are listed in Table 3 along with the failure modes.

Table 3. Comparison between load-carrying capacities and characteristic failure mode

\begin{tabular}{|c|c|c|c|c|}
\hline $\begin{array}{c}\text { Test } \\
\text { specimen }\end{array}$ & $\begin{array}{l}\text { Flexural } \\
\text { load }\end{array}$ & $\begin{array}{l}\text { Average } \\
\text { load }\end{array}$ & Ratio & Failure modes \\
\hline I-M-1 & 80.9 & \multirow[b]{2}{*}{83.0} & \multirow[b]{2}{*}{-} & Flexural failure \\
\hline I-M-2 & 85.1 & & & Flexural failure \\
\hline I-R-1 & 69 & \multirow[b]{2}{*}{69} & \multirow[b]{2}{*}{$\mathrm{R} / \mathrm{M}=0.83$} & Flexural failure \\
\hline I-R-2 & 70 & & & Flexural failure \\
\hline I-C.M-1 & 120.9 & \multirow[b]{2}{*}{120.3} & \multirow[b]{2}{*}{ C.M/M = 1.45} & Flexural Failure \\
\hline I-C.M-2 & 119.7 & & & Flexural failure \\
\hline I-C.R-1 & 109.7 & \multirow[b]{2}{*}{109.4} & C.R/R = 1.58 & Shear failure \\
\hline I-C.R-2 & 109.2 & & \multirow[t]{2}{*}{$\mathrm{C} . \mathrm{R} / \mathrm{CM}=0.91$} & Shear failure \\
\hline II-M-1 & 105.6 & \multirow[b]{2}{*}{102.9} & & Flexural failure \\
\hline II-M-2 & 100.1 & & - & Flexural failure \\
\hline II-R-1 & 84.6 & \multirow[b]{2}{*}{87.2} & \multirow[b]{2}{*}{$\mathrm{R} / \mathrm{M}=0.85$} & Flexural failure \\
\hline II-R-2 & 89.8 & & & Flexural failure \\
\hline II-C.M-1 & 139.8 & \multirow{2}{*}{137.5} & \multirow{2}{*}{ C.M/M = 1.34} & Flexural failure \\
\hline II-C.M-2 & 135.1 & & & Flexural failure \\
\hline II-C.R-1 & 124.7 & \multirow[b]{2}{*}{122.2} & C.R/R = 1.40 & Shear failure \\
\hline II-C.R-2 & 119.7 & & \multirow{2}{*}{ C.R/C.M = 0.89} & Shear failure \\
\hline III-M-1 & 95.3 & 95.3 & & Flexural failure \\
\hline III-R-1 & 69.4 & 69.4 & $\mathrm{R} / \mathrm{M}=0.73$ & Shear failure \\
\hline III-C.M-1 & 109.5 & 109.5 & C.M $/ \mathrm{M}=1.15$ & Shear failure \\
\hline III-C.R-1 & 75.7 & 75.7 & $\begin{array}{c}\text { C.R } / \mathrm{R}=1.09 \\
\text { C.R/C.M }=0.69\end{array}$ & $\begin{array}{l}\text { Shear failure } \\
\text { Shear failure }\end{array}$ \\
\hline
\end{tabular}

*I: Type I, II: Type II, III: Type III; M: Flexutal test under static; R: Test under running load; C: CFS; 1, 2: Test specimen No. 


\section{(1) Non-reinforced RC beams}

As shown in Table 3, the load-carrying capacity ratios between the non-reinforced $\mathrm{RC}$ beam subjected to running loads and those subjected to static loads (R/M) were $0.83,0.85$ and 0.73 for Types I, II and III, respectively. The load-carrying capacities for Types I, II, and III due to the running loads decreased by $17 \%$, $15 \%$, and $27 \%$, respectively.

For the static loading, all three types failed in flexure under the loading point. With respect to the specimens subjected to running loads, while Types I and II failed in flexure at the center of span, Type III failed in shear at $55 \mathrm{~cm}$ away from Support A.

\section{(2) CFS-reinforced RC beams}

As shown in Table 3, the load-carrying capacity ratios between the CFS-reinforced beam and non-reinforced RC beam subjected to static loads (CM/M) was 1.45 and 1.34 , respectively, that CFS greatly improves the beam strength under static loading for Types I and II. Type III showed shear failure and the ratio between the CFS-reinforced beam and non-reinforced beam was 1.15. Since the CFS-reinforced beam specimen failed in shear, the strength improvement by CFS was less significant than Types I and II.

CFS-reinforced beams of Types I and II subjected to static load failed in flexure. Although the Type III had the first early flexural cracks as the loads increased, it ultimately failed in shear. Under the running load, all CFS-reinforced RC beams failed in shear: Type I failed at $45 \mathrm{~cm}$ away from Support A, and Types II and III at $55 \mathrm{~cm}$ away from Support B.

\section{RELATIONSHIP BETWEEN LOAD AND STRAIN}

\section{Strain induced in tensile reinforcement}

Figure 4 expresses the relationship between the strain that induced in the tensile reinforcement at the center of span and the load that was the static load located at the center of the span. The relationship between the strain and the load in the shear experiments on specimens under the static load was not given because the experimental methods were different from the former. The observed yield strains of reinforcements were $1,840 \times 10^{-6}$ for Types I and II and $1,885 \times 10^{-6}$ for Type III. On the other hand, the theoretical strain calculated from the physical properties listed in Table 1 was approximately $1,850 \times 10^{-6}\left(=370 \mathrm{~N} / \mathrm{mm}^{2} / 200 \times\right.$ $10^{3} \mathrm{~N} / \mathrm{mm}^{2}$ ), which approximately agrees with the experimental values.

\section{(1) Strains induced in non-reinforced $R C$ beams}

The yield loads of the tensile reinforcement in the Type I under the static and running loads were $65 \mathrm{kN}$ and $55 \mathrm{kN}$ as can be seen in Figure 4. The ratio of yielding load under the running load to the static load was $0.85(=55 \mathrm{kN} / 65 \mathrm{kN})$ for Type I. In case of Type II, the yielding loads under the static and running load were $75 \mathrm{kN}$ and $65 \mathrm{kN}$ on average for a ratio of 0.87 (= $65 \mathrm{kN} / 75 \mathrm{kN})$. The tensile reinforcements contributed to maintaining the load-carrying capacity of the speci-

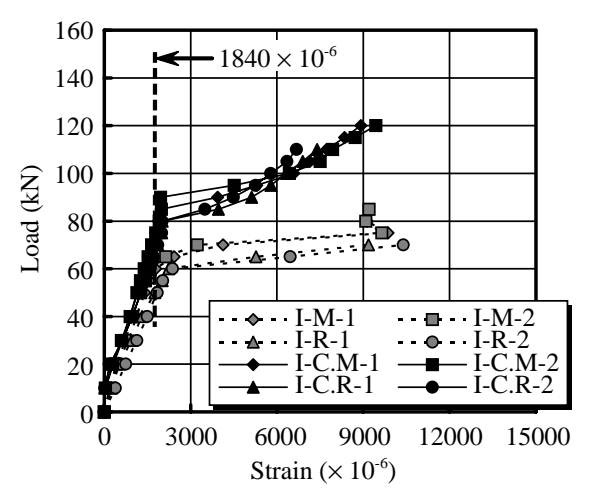

(1) Type I

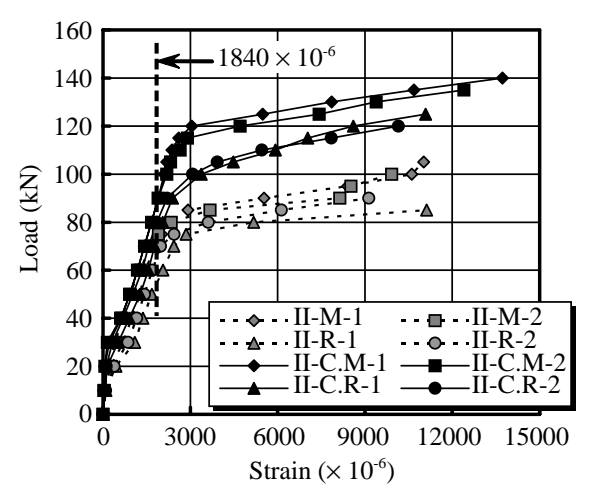

(2) Type II

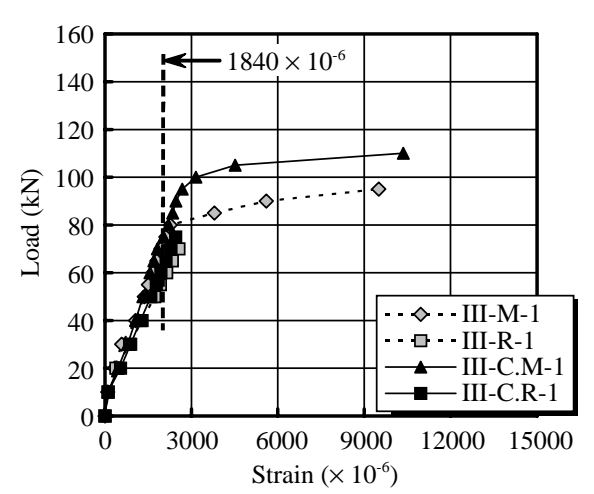

(3) Type III

Fig. 4. Load-strain relation in tensile reinforcement at center of span. 
mens even after the yield. In the case of Type III, the yielding loads under the static and running load were 65 $\mathrm{kN}$ and $50 \mathrm{kN}$ on average, respectively. At the ultimate stage, the specimen suffered the shear failure; so, the strain in the reinforcement increased only marginally to $2,500 \times 10^{-6}$. The ratio of yielding loads was 0.77 (= $50 \mathrm{kN} / 65 \mathrm{kN}$ ) between the running load and the static load. The specimen suffered the shear failure after the yielding of tensile reinforcement.

\section{(2) Strains induced in CFS-reinforced RC beams}

In the Figure 4, the yield load of tensile reinforcement in the Type I under the static load was $87.5 \mathrm{kN}$. In the post-yield loading region, the strengthening effect of the CFS was noticeable. Therefore, the strain increased, though gradually and almost linearly with the loading. Under the running load, the primary reinforcement began to yield at $80 \mathrm{kN}$ and the gradual increase in strain was observed, just as with the static loading. For the Type II, the yield load of the tensile reinforcement under the static load was $105 \mathrm{kN}$. Under the running load, the reinforcement began to yield at 85 $\mathrm{kN}$. In the case of the Type III, the reinforcement began to yield at $75 \mathrm{kN}$ and $60 \mathrm{kN}$ under the static and the running load, respectively. Since this specimen suffered the shear failure, the gradual increase in strain was observed.

In summary, under the static and running load, the load-carrying capacities of specimens were maintained by the reinforcing effect of the CFS, the strain increased reinforcing effect of the CFS and the strain increased linearly even after the yielding of the tensile reinforcements.

\section{Strains induced in CFS}

Figure 5 indicates the relationship between the strain induced in the CFS at the center of the span and the load. Although the nominal ability of fracture strain of CFS was $18,190 \times 10^{-6}\left(=4420 \mathrm{~N} / \mathrm{mm}^{2} / 243 \times\right.$ $10^{3} \mathrm{~N} / \mathrm{mm}^{2}$ ), the actual strains exceeding $20,000 \times 10^{-6}$ were measured during the loading. Taking into account the reliability of the data, a strain of $20,000 \times 10^{-6}$ should be adopted as the maximum strain in the Figure 5 [10].

In the case of Type I and II under the static load, the strain in the CFS increased linearly beyond the yield load of tensile reinforcements. In general, the strain at which the CFS peels was approximately $6,000 \times 10^{-6}$. However, no remarkable increase in the strain that would cause the CFS to fracture was observed even beyond the nominal peeling strain. For the Type III, the failure mode was the shear failure, and the strain at the ultimate state was approximately $7,500 \times 10^{-6}$. Under the running load, all specimen types suffered the shear failure during motion of the wheel, and therefore, the gradual increase in the strain at the center of the span was observed. Particularly, the strain at a load of $80 \mathrm{kN}$ for the Type III was approximately $2,800 \times 10^{-6}$.

For specimens that suffered the shear failure during motion of the wheel, the strain in the CFS at locations of $10 \mathrm{~cm}$ and $190 \mathrm{~cm}$ away from Support A remained below only $200 \times 10^{-6}$ at the maximum loadcarrying capacity. Accordingly, the CFS peeled simultaneously with the shear failure.

\section{COMPARISON OF THEORETICAL AND EXPERIMENT STRENGTH}

\section{Theoretical load-carrying capacity equations}

In this paper, the theoretical flexural and shear load-carrying capacities are evaluated by using equations for the ultimate flexural and shear load-carrying capacities while taking into consideration for the failure

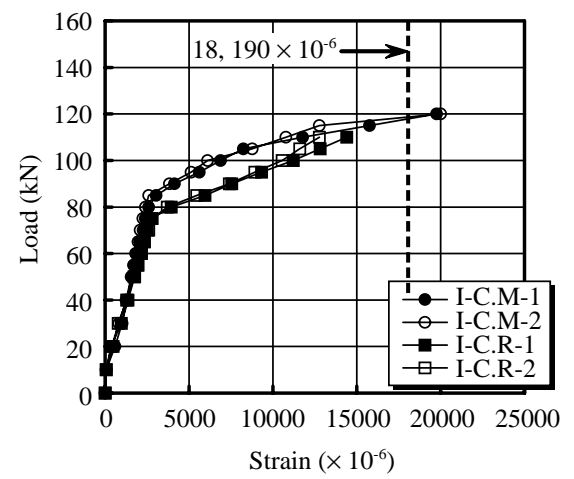

(1) Type I

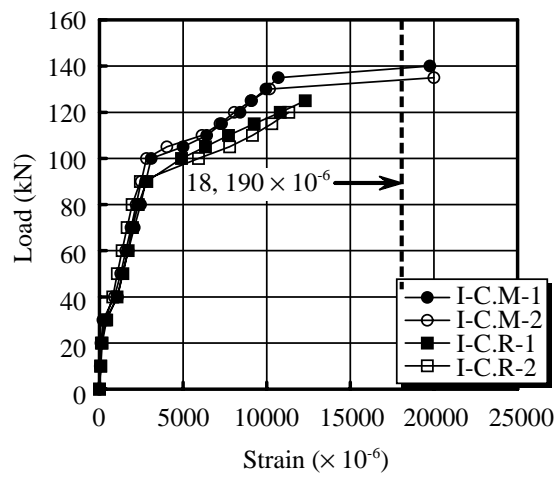

(2) Type II

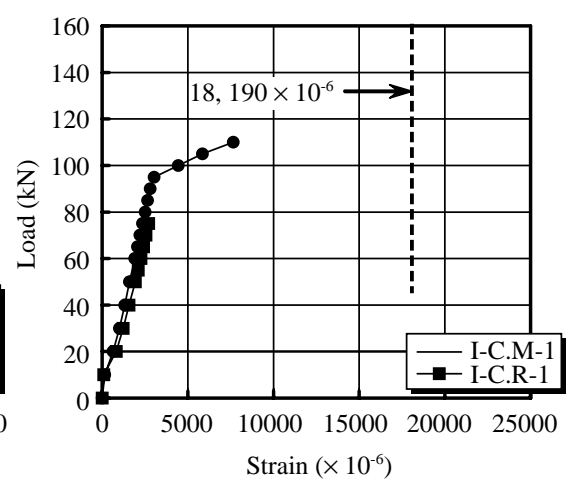

(3) Type III

Fig. 5. Load-strain relation in CFS at center of span. 
mode.

\section{(1) Ultimate flexural load-carrying capacity}

The theoretical flexural load-carrying capacity, $P_{u}$, of the experimental beam can be calculated from the ultimate flexural load-carrying capacity equation for the rectangular cross-section with reinforcements on both tension and compression sides on the basis of the ultimate limit-state design method. The height of the equivalent stress block, a, is not larger than the thickness of the upper cover concrete for all specimen types. Accordingly, the flexural ultimate moment, $M_{u}$, of the specimen is given by the following Eq. (1):

$$
M_{u}=A_{s} \cdot f_{y d} \cdot(d-a / 2)+A_{s}^{\prime} \cdot \sigma_{s}^{\prime}\left(d^{\prime}-a / 2\right)
$$

where, $f_{y d}$ is the yielding strength of reinforcement, $\sigma_{s}{ }^{\prime}$ is the stress of compression reinforcement, $A_{s}$ is the amount of reinforcement on tension side, $A_{s}{ }^{\prime}$ is the amount of reinforcement on compression side, $d$ is the effective depth, $d^{\prime}$ is the upper thickness of covering concrete, and a is the height of equivalent stress block.

The theoretical flexural load-carrying capacity, $P_{u}$, is calculated from the following Eq. (2):

$$
P_{u}=4 \cdot M_{u} / L
$$

where, $L$ is the span length.

The experimental and theoretical results for the flexural load-carrying capacity of non-reinforced RC beams, derived from Eqs. (1) and (2), are shown in Table 4. A comparison of the experimental and the theoretical values for non-reinforced RC beams shows that the ratio of the experimental to the theoretical is $1.16,1.14$, and 1.13 for Types I, II, and III under the static load, respectively. Under the running load, the ratio is 0.97 for all specimen types. Accordingly, a load-carrying capacity reduction factor needs to be added to Eq. (1) in the event of calculating the flexural load-carrying capacity of beam under the running load.

\section{(2) Shear load-carrying capacity of specimens without shear reinforcement}

According to the Specifications for Concrete [4], the design shear load-carrying capacity of the RC beam is given by the equation below.

\section{Design shear load-carrying capacity:}

$$
V_{c d}=\beta_{d} \cdot \beta_{p} \cdot \beta_{n} \cdot f_{v c d} \cdot b_{w} \cdot d / \gamma_{b}
$$

\begin{tabular}{|c|c|c|c|c|}
\hline \multirow{2}{*}{$\begin{array}{c}\text { Test } \\
\text { specimen }\end{array}$} & \multicolumn{3}{|c|}{ Flexural load-carrying capacity $(\mathrm{kN})$} & \multirow{2}{*}{$\begin{array}{c}\text { Experimental } \\
\text { theoretical value }\end{array}$} \\
\hline & Experimental & & & \\
\hline I-M-1 & 80.9 & 71.7 & Eqs. (1) and (2) & 1.13 \\
\hline I-M-2 & 85.1 & & & 1.19 \\
\hline I-R-1 & 68.9 & 71.7 & Eqs. (1) and (2) & 0.96 \\
\hline I-R-2 & 69.6 & & & 0.97 \\
\hline I-C.M-1 & 120.9 & 93.1 & Eqs. (5) and (2) & 1.30 \\
\hline I-C.M-2 & 119.7 & & & 1.29 \\
\hline I-C.R-1 & 109.7 & 86.8 & Eqs. (3) and (4) & 1.26 \\
\hline I-C.R-2 & 109.2 & & & 1.26 \\
\hline II-M-1 & 105.6 & 90.1 & Eqs. (1) and (2) & 1.17 \\
\hline II-M-2 & 100.1 & & & 1.11 \\
\hline II-R-1 & 84.6 & 90.1 & Eqs. (1) and (2) & 0.94 \\
\hline II-R-2 & 89.8 & & & 1.00 \\
\hline II-C.M-1 & 139.8 & 113.7 & Eqs. (5) and (6) & 1.23 \\
\hline II-C.M-2 & 135.1 & & & 1.19 \\
\hline II-C.R-1 & 124.7 & 103.9 & Eqs. (3) and (4) & 1.20 \\
\hline II-C.R-2 & 119.7 & & & 1.15 \\
\hline III-M-1 & 95.3 & 84.7 & Eqs. (1) and (2) & 1.13 \\
\hline III-R-1 & 69.4 & 71.2 & Eqs. (3) and (4) & 0.97 \\
\hline III-C.M-1 & 109.5 & 103.7 & Eqs. (5) and (2) & 1.06 \\
\hline III-C.M-1 & 75.7 & 71.2 & Eqs. (3) and (4) & 1.06 \\
\hline
\end{tabular}

where,

Table 4. Experimental and theoretical load-carrying capacities 


$$
\begin{aligned}
& \beta_{d}=\sqrt[4]{1 / d}, \quad\left(\beta_{d}=1.5 \text { for } \beta_{d}>1.5\right) \\
& \beta_{p}=\sqrt[3]{100 p w},\left(\beta_{p}=1.5 \text { for } \beta_{p}>1.5\right) \\
& p_{w}=A_{s} /\left(b_{w} \cdot d\right), \\
& \beta_{n}=1, \\
& f_{v c d}=0.20 \sqrt{f_{c d}^{\prime}},\left(\text { for this experiment } f_{c d}^{\prime}=f_{c}^{\prime}\right) \\
& \gamma_{b}=1
\end{aligned}
$$

Shear load-carrying capacity:

$$
P_{s u}=V_{c d} \cdot L /\left(L-x_{0}\right)
$$

where, $\beta_{d}$ is the size effect factor, $\beta_{p}$ is the influence factor for reinforcement ratio's, $\beta_{n}$ is the axial loading factor of shear capacity, $p_{w}$ is the reinforcement ratio, $b_{w}$ is the width of beam, $d$ is the effective depth, $x_{0}$ is the distance between support and the loading point, $f_{c d}^{\prime}$ is the design concrete compression strength, $f_{c}^{\prime}$ is the concrete compression strength, $\gamma_{b}$ is the member factor (when there is an experiment, $\gamma_{b}$ is 1 ) and $L$ is the span length.

\section{(3) Flexural load-carrying capacity of CFS-reinforced RC beams}

The flexural load-carrying capacity of RC beams reinforced with the CFS has been analyzed by using many experiment results. Sakai et al., proposed Eq. (5) for the ultimate flexural load-carrying capacity when the CFS is bonded to the bottom only [13]. In this case, the theoretical maximum flexural load-carrying capacity is calculated by using Eq. (2).

$$
\begin{aligned}
M_{u c} & =\left(0.90 \cdot A_{s} \cdot f_{y d} \cdot d\right) \\
& +\left(0.90 \cdot A_{c s} \cdot E_{f} / E_{s} \cdot f_{y c} \cdot a \cdot h\right)
\end{aligned}
$$

where, $A_{S}$ is the amount of reinforcement on the tension side, $f_{y d}$ is the yield strength of reinforcement, $d$ is the effective depth, $A_{c s}$ is the cross-sectional area of the CFS (Table 2), $E_{s}$ is the Young's modulus of reinforcement, $E_{f}$ is the Young's modulus of the CFS, $f_{y c}$ is the tensile strength of the CFS, a is the reduction factor $(=1 / 2)$, and $\mathrm{h}$ is the height of beam.

Table 4 shows the flexural load-carrying capacities of CFS-reinforced RC beams obtained from the experimental and those derived from the theoretical equation by Sakai et al. [13].

Comparing the experimental results and the theoretical results for static loading (derived from Eq. (5) and Eq. (2)), we see that, on average, the experimental is 1.29 times and 1.21 times larger than the theoretical for Types I and II. The reason for this relatively large discrepancy may depend on that, since the reinforcements used in the specimens were rusted, their yield strengths as well as the tensile strength of CFS are multiplied by a reduction factor of 0.9 in Eq. (5). In additional, the reduction factor of the CFS strain at peeling is reduced by half $(a=1 / 2)$, and therefore, the calculated results are on the safe side. For the Type III, the ratio is 1.06 because this specimen suffered the shear failure, and the CFS has the little reinforcing effect.

Under the running load, all specimen types are suffered from the shear failure. Comparing the experimental results for the ultimate shear load-carrying capacity of CFS-reinforced RC beams with the theoretical results for non-reinforced RC beams (given by Eqs. (3) and Eq. (4)), the ratios between them are 1.26, 1.18, and 1.06 for specimen Types I, II, and III, respectively. However, there is a little difference between the experimental shear load-carrying capacity of specimens without the CFS reinforcement and the specimens reinforced with the CFS in the shear span.

\section{Proposal on the ultimate flexural load-carrying capac- ity equation for CFS-reinforced beam}

\section{(1) Ultimate flexural load-carrying capacity of beam under static load}

The authors have corrected the ultimate flexural load-carrying capacity equation, taking into account the strain hardening of primary reinforcement, and proposed Eqs. (6) and (7) for the ultimate flexural loadcarrying capacity of beams under the static and the running load. These theoretical equations are approximately to the values measured experimentally [2].

Ultimate flexural load-carrying capacity of beam under static load:

$$
\begin{aligned}
M_{u s} & =\left\{1.13 \cdot A_{s} \cdot f_{y d} \cdot(d-a / 2)\right\} \\
& +A_{s}{ }^{\prime} \cdot \sigma_{s}{ }^{\prime}\left(d^{\prime}-a / 2\right)
\end{aligned}
$$

Ultimate flexural load-carrying capacity of beam under running load:

$$
\begin{aligned}
M_{u R} & =M_{u s} / \rho_{M}=\left\{1.13 \cdot A_{s} \cdot f_{y d} \cdot(d-a / 2)\right. \\
& \left.+A_{s}^{\prime} \cdot \sigma_{s}^{\prime}\left(d^{\prime}-a / 2\right)\right\} / \rho_{M}
\end{aligned}
$$

where, $\rho_{M}$ is the load correction coefficient. 
Table 5. Coefficients of CFS reinforcing effect

\begin{tabular}{cccc}
\hline Test specimen & Type I & Type II & Type III \\
\hline Maximum strain of CFS in linear increase part $\varepsilon_{y c f}\left(\times 10^{-6}\right)$ & 10,697 & 12,767 & 5,800 \\
Nominal fracture strain of CFS $\varepsilon_{y}\left(\times 10^{-6}\right)$ & 10,171 & 11,767 & \\
Coefficient of CFS reinforcing effect $\beta_{c f}=\varepsilon_{y c f} / \varepsilon_{y}$ & 18,189 & 18,189 & 18,189 \\
Beam as spect ratio $\left(b_{w} / h\right)$ & 0.59 & 0.70 & 0.32 \\
\hline
\end{tabular}

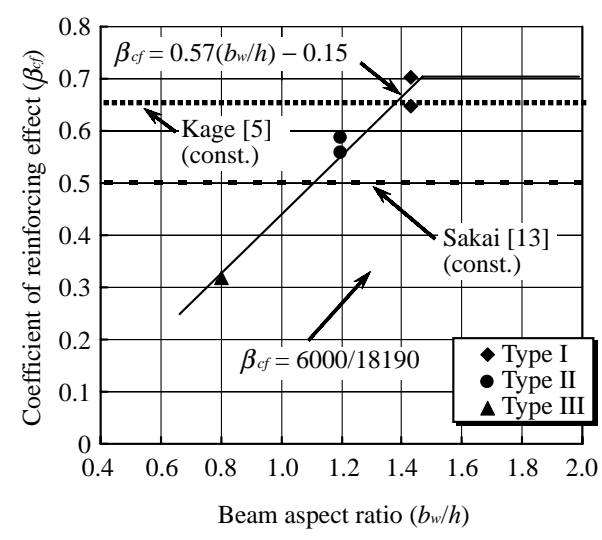

Fig. 6. Coefficient of CFS reinforcing effect as a function of beam aspect ratio.

\section{(2) Coefficient of reinforcing effect of CFS considering as- pect ratio}

In Eq. (5) proposed by Sakai et al., the tensile loadcarrying capacity of the CFS is multiplied by a reduction factor $a(=1 / 2)$ [13]. In the later work, Rokugo et al., calculated the flexural load-carrying capacity of beams reinforced with the CFS by using the reduction factors a of $1 / 3$ and $2 / 3$ (corresponding to a peel-off area rate of $56 \%$ ). In this experimental results, as the relationship between aspect ratio and coefficient of reinforcing effect in Figure 6, coefficient of reinforcing effect varies with the type of specimen or its aspect ratio; additional, using the reduction factor as described in the reference [5] will result in variations in the flexural load-carrying capacity of beams reinforced with the CFS.

The authors have defined the ratio of the linear increase in the maximum strain to the strain at which CFS fractures as a coefficient for the reinforcing effect of CFS $\left(\beta_{c f}\right)$ and calculated the ultimate flexural load-carrying capacity of CFS-reinforced RC beams by multiplying the tensile load-carrying capacity of CFS by this coefficient, which is derived from Eq. (8) below:

$$
\beta_{c f}=e_{y c f} d e_{y}
$$

where, $e_{y c f}$ is the maximum strain of CFS, and $e_{y}$ is the fracture strain of CFS.

Table 5 shows the coefficient for the reinforcing effect of CFS derived from the ratio of the maximum strain to the fracture strain of CFS using Eq. (7). The coefficient for the reinforcing effect of CFS $\left(\beta_{c f}\right)$ is shown in Figure 6 as the relationship with the ratio of beam width $\left(b_{w}\right)$ to beam height $(h)$ (the aspect ratio $=$ $\left.b_{w} / h\right)$. Using the peel-off strain and fracture strain of CFS $\left(6000 \times 10^{-6}\right.$ and $\left.18190 \times 10^{-6}\right)$, the reduction factor is calculated to be 0.33 .

Figure 6 also shows the relationship between the aspect ratio $\left(b_{w} / h\right)$ and the coefficient for the reinforcing effect of CFS $\left(\beta_{c f}\right)$ is given by Eq. (9).

$$
\beta_{c f}=0.57\left(b_{w} / h\right)-0.15\left(\beta_{c f}=0.7 \text { for } \beta_{c f}>0.7\right)
$$

where, $b_{w}$ is the width of beam, and h is the height of beam.

\section{(3) Ultimate flexural load-carrying capacity of CFS-rein- forced RC beams}

The ultimate flexural load-carrying capacity of a CFS-reinforced RC beam can be calculated by adding the ultimate flexural loading capacity of CFS to the ultimate flexural load-carrying capacity of a non-reinforced RC beam derived from Eq. (6). Accordingly, the ultimate flexural load-carrying capacity of the RC beam reinforced with the CFS under static load can be expressed by the equation as below.

$$
\begin{aligned}
M_{u c} & =\left\{1.13 \cdot A_{s} \cdot f_{u d} \cdot(d-a / 2)\right\}+A_{s}{ }^{\prime} \\
\cdot & \sigma_{s}{ }^{\prime}\left(d^{\prime}-a / 2\right)+\left\{0.90 \cdot A_{c s} \cdot f_{y c f} \cdot \beta_{c f}(h-x / 2)\right.
\end{aligned}
$$

where, $\beta_{c f}$ is from Eq. (9), $A_{c s}$ is the cross-sectional area of CFS (Table 2), $f_{y c f}$ is the tensile load-carrying capac- 
ity of the CFS, $\beta_{c f}$ is the coefficient of reinforcing effect, $b_{w}$ is the width of RC beam, and $\mathrm{h}$ is the height of beam.

In Eq. (10), the yield strength of the reinforcements is set to $1.13 \cdot A_{s} \cdot f_{y d}$ (multiplying by an increase factor of 1.13) that the specimen is an undamaged RC beam, and its strength remains after the yielding of the reinforcements due to the strain hardening. On the other hand, Sakai et al., proposed using $0.90 \cdot A_{s} \cdot f_{y d}$ (multiplying by a reduction factor of 0.9 ), that the tensile reinforcements were rusted. In addition, in Eq. (9), although the coefficient for the reinforcing effect of CFS is taken into consideration, the tensile strength of CFS is set to $0.90 \cdot A_{c s} \cdot f_{y c f} \cdot \beta_{c f}$ (multiplying by a reduction factor of 0.9 ) so that a conservative result can be obtained.

Summarizing the above, the ultimate flexural loadcarrying capacity and the theoretical flexural load-carrying capacity non-reinforced $\mathrm{RC}$ beam subject to static loads are calculated by Eq. (6) and Eq. (2), and those of the non-reinforced RC beams subject to running loads are calculated by Eq. (7) and Eq. (2). The ultimate flexural load-carrying capacity of a CFS-reinforced RC beam subject to static load is calculated by Eq. (10) and Eq. (2). The theoretical flexural load-carrying capacities are shown in Table 6. For running loads, since all specimens failed in shear, the results are not shown in Table 6.

\section{Comparison between experimental and theoretical results}

\section{(1) Non-reinforced RC beams}

The theoretical flexural load-carrying capacity of specimens without the reinforcement under the static load is calculated by using Eq. (6) and Eq. (2), that given a ratio of approximately $1.04,1.03$, and 1.01 times of the theoretical load-carrying capacity for the Types I, II, and III. For specimens under the running load (Eq. (7) and Eq. (2)), the load-carrying capacity of the experimental is approximately 1.04 times of the theoretical load-carrying capacity for the Types I and II.

\section{(2) CFS-reinforced RC beams}

The ultimate load-carrying capacity of specimens reinforced with CFS under the static load is calculated by using Eq. (10) and Eq. (2) with the reinforcing effect coefficient obtained in the present paper. The experimental load-carrying capacities are approximately $1.05,1.02$, and 1.03 times of the theoretical values for the Types I, II, and III, respectively.

\section{CONCLUSION}

(1) The flexural load-carrying capacities of non-reinforced RC beams under the running load were $17 \%$ and $16 \%$ lower than the static load for the Types I and II. The Type III suffered the shear failure.

(2) The failure modes of RC beams reinforced with the CFS under the static load were the flexural failure for the Types I and II, and the shear failure was for the Type III. Under the running load, the mode was the shear failure for all specimen types. In any case, the fracture failure was never occurred to the CFS that peeled away from the concrete surface by virtue of the tensile stresses at the center of the RC beam.

(3) The reinforcing effect of CFS on RC beams was

Table 6. Experimental and proposed load-carrying capacities

\begin{tabular}{|c|c|c|c|c|}
\hline \multirow{2}{*}{$\begin{array}{c}\text { Test } \\
\text { specimen }\end{array}$} & \multicolumn{3}{|c|}{ Flexural load-carrying capacity (kN) } & \multirow{2}{*}{$\begin{array}{l}\text { Experimental } \\
\text { theoretical value }\end{array}$} \\
\hline & Experimental & & & \\
\hline I-M-1 & 80.9 & & & 1.02 \\
\hline $\mathrm{I}-\mathrm{M}-2$ & 85.1 & 79.6 & Eqs. (6) and (2) & 1.07 \\
\hline I-R-1 & 68.9 & & & 1.03 \\
\hline I-R-2 & 69.6 & 66.9 & Eqs. (7) and (2) & 1.04 \\
\hline I-C.M-1 & 120.9 & & & 1.05 \\
\hline I-C.M-2 & 119.7 & 11.6 & Eqs. (10) and (2) & 1.04 \\
\hline II-M-1 & 105.6 & & & 1.05 \\
\hline II-M-2 & 100.1 & 100.3 & Eqs. (6) and (2) & 1.00 \\
\hline II-R-1 & 84.6 & & & 1.00 \\
\hline II-R-2 & 89.8 & 84.2 & Eqs. (7) and (2) & 1.07 \\
\hline II-C.M-1 & 139.8 & & & 1.07 \\
\hline II-C.M-2 & 135.1 & 131.1 & Eqs. (10) and (2) & 1.03 \\
\hline III-M-1 & 95.3 & & & 1.01 \\
\hline III-R-1 & 69.4 & 94.7 & Eqs. (6) and (2) & \\
\hline III-C.M-1 & 109.5 & 106.7 & Eqs. (10) and (2) & 1.03 \\
\hline
\end{tabular}


$45 \%, 34 \%$, and $15 \%$ for the Types I, II, and III, respectively, as compared with non-reinforced RC beams. These results indicate that the flexural loadcarrying capacity varies with the aspect ratio of beam.

(4) The tensile load-carrying capacity of CFS, which is required to calculate the ultimate load-carrying capacity of an RC beam reinforced with CFS, is affected greatly by the aspect ratio $\left(b_{w} / h\right)$ of the beam. Thus, the authors have proposed the coefficient of reinforcing effect of CFS as a function of the aspect ratio.

(5) It has been verified that the general flexural loadcarrying capacity of $\mathrm{RC}$ beam reinforced with the CFS can be well evaluated by using a coefficient of reinforcing effect proposed by this paper.

\section{REFERENCES}

1. Abe, T., Kida, T., Sawano, T., Hoshino, M., and Kato, K., "Load-Carrying Capacity and Dynamical Effects of RC Beams Subjected to Running Load and Variable Load," Journal of Structural Engineering, Vol. 47A, pp. 313-320 (2001).

2. Abe, T., Kida, T., Sawano, T., Hoshino, M., and Kato, K., "Flexural Load-Carrying Capacity and Failure Mechanism of RC Beams with Low Effective Depth under Running Wheel-Load," Materials Science Research International, Vol. 7, No. 3, pp. 186-193 (2001).

3. Anania, L., Badala, A., and Failla, G., "Increasing the Flexural Performance of RC Beams Strengthened with CFRP Materials," Construction and Building Materials, pp. 55-61 (2005)

4. Japan Society of Civil Engineers, Standard Specifications for Concrete Structures-2002 Structural Performance Verification (JSCE Guidelines for Concrete No. 3), Tokyo, Japan (2005).

5. Kage, T. and Masuda, Y., "Influence of Separation on Flexural Performance of RC Beam Reinforced by CFRPSheets," Proceedings of the Japan Concrete Institute, Vol. 20, No. 1, pp. 425-430.

6. Kawakami, Y., Kida, T., Abe, T., and Kato, K., "Fundamental Research on Characteristic of RC Beam to Moving Load," Cement Science and Concrete Technology,
Vol. 57, pp. 368-373 (2003).

7. Kida, T., Abe, T., Yanai, M., and Kato, K., "Running Load Carrying Capacity of RC Beam Strengthened with CFS and its Rehabilitation Effect," Proceedings of the Japan Concrete Institute, Vol. 24, No. 2, pp. 1447-1452 (2002).

8. Kurihashi, Y., Kishi, N., Mikami, H., and Matsuoka, K., "Flexural Bonding Property of FRP Sheet on RC Beam with Two-point Loading," Proceedings of the Japan Concrete Institute, Vol. 21, No. 3, pp. 1555-1560 (1999).

9. Lee, J.K. and Lee, J.H., "Nondestructive Evaluation on Damage of Carbon Fiber Sheet Reinforced Concrete," Composite Structures, Vol. 58, No. 1, pp. 139-147 (2002).

10. Mikami, H., Kishi, N., Sato, M., and Kurihashi, Y., "Effect of Strengthened Area on Bending Capacity of RC Beams Adhered with FRP Sheet," Proceedings of the Japan Concrete Institute, Vol. 21, No. 3, pp. 1549-1554 (1999).

11. Oh, S., Hoshino, M., and Abe, T., "Influence on Effect of Load-Carrying Capacity of RC Beam Under Moving Load," Proceeding of the $54^{\text {th }}$ Annual Conference of the Japan Society of Civil Engineers, Tokyo, Japan, V-299, pp. 598-599 (1999).

12. Oh, H., Sim, J., and Meyer, C., "Experimental Assessment of Bridge Deck Panels Strengthened with Carbon Fiber Sheets," Composites Part B: Engineering, Vol. 34, No. 6, pp. 527-538 (2003).

13. Sakai, H., Tomosawa, F., Masuda, Y., Abe, M., Noguchi, T., Kage, T., Lee, H.S., and Hisabe, N., "CFRP Sheet Strengthening of Reinforced Concrete Members Damaged by Rebar Cossion," Summaries of Technical Papers of Annual Meeting Architectural Institute of Japan, pp. 345-346 (1996).

14. Takahashi, Y., Hata, C., Maeda, T., and Sato, Y., "Experimental Study of Flexural Behavior of Aramid FRP Rods Reinforced Concrete Beam with Externally Bonded Carbon Fiber Sheet," Proceedings of the Japan Concrete Institute, Vol. 20, No. 1, pp. 509-514 (1998).

15. Takeda, K., Mitsui, U., Murakami, K., Sakai, H., and Nakamura, M., "Flexural Behaviour of Reinforced Concrete Beams Strengthened with Carbon Fibre Sheets," Composites Part A: Applied Science and Manufacturing, Vol. 27, No. 10, pp. 981-987 (1996). 